- One hundred and sixty-nine reinforced glass ionomer restorations in posterior teeth were assessed in three UK dental practices.

- Ninety-eight percent of these restorations were performing satisfactory at two years.

- Further assessment by an independant observer is indicated.

\title{
Clinical performance of reinforced glass ionomer restorations placed in UK dental practices
}

\author{
F. J. T. Burke, ${ }_{1}^{1}$ C. Siddons, ${ }_{1}^{2}$ S. Phipps, ${ }^{3}$ J. Bardha, ${ }_{1}^{4}$ R. J. Crisp ${ }^{5}$ and B. Dopheide ${ }^{6}$
}

Aim To retrospectively evaluate the performance of reinforced glass ionomer restorations placed in load-bearing surfaces of posterior teeth in three UK general dental practices.

Methods Inclusion criteria for the participating practitioners were that they would be able to find, in their regularly attending patients' mouths, a minimum of 30 Fuji IX restorations placed in load-bearing cavities in posterior teeth. The three practitioners who agreed to participate were given training in the methods of assessment of restorations. Presence/absence of the restoration, presence of secondary caries, anatomic form, margin adaptation, margin discolouration, surface roughness and colour match were recorded.

Results Three general dental practitioners and 169 restorations in 116 patients were included in the study. Seventy-eight percent of restorations were placed in molar teeth, the remainder in premolar teeth, with 67 being Class I and 102 Class II. The mean age of restorations at examination was 25 months, ranging from five months to 56 months. Of the restorations examined, $98 \%(n=166)$ were found to be present and intact. No secondary caries was detected clinically. Three restorations were found to have fractured.

Conclusion Reinforced glass ionomer restorations placed in loadbearing situations in patients attending three dental practices in the UK were found to be performing satisfactorily at two years. Further investigations, of improved rigour, may now be indicated to more fully assess the performance of such restorations in the long term.

\footnotetext{
1*Professor of Primary Dental Care, Primary Dental Care Research Group, University of Birmingham School of Dentistry, St Chad's Queensway, Birmingham, B4 6NN; ${ }^{2}$ General Dental Practitioner, Ilkley, Yorkshire; ${ }^{3}$ General Dental Practitioner, Beaconsfield, Buckinghamshire; ${ }^{4}$ General Dental Practitioner, Birmingham; ${ }^{5}$ Researcher, Primary Dental Care Research Group, University of Birmingham School of Dentistry, St Chad's Queensway, Birmingham, B4 6NN; ${ }^{6}$ Director of Product Managament, GC Europe, Leuven, Belgium

${ }^{*}$ Correpondence to: Professor Trevor Burke

Email:f.j.t.burke@bham.ac.uk
}

Online article number E2

Refereed Paper - accepted 3 August 2006

DOI: $10.1038 /$ bdj.2007.529

${ }^{\circ}$ British Dental Journal 2007; 203: E2

\section{INTRODUCTION}

Practice-based research

A majority of research into the effectiveness of dental materials is carried out in dental hospitals or other academic institutions, rather than in primary dental care/general dental practice where the majority of dental treatment, worldwide, is performed. Reasons for this include the potential cost of practice-based research, given that practices are geared to the efficient treatment of patients, and time is not budgeted for research. ${ }^{1}$ Additionally, the training of general practitioners in research methods may be incomplete. However, there are many reasons why dental practice increasingly should become the prime location for clinical dental research. Dental practice is the real world. Accordingly, if a technique or material is to be successful, it must be appropriate to the dental practice situation.

A variety of types of research may be considered particularly appropriate to dental practice. These include clinical trials of materials and techniques, assessment of treatment trends, and assessment of dentists' behaviour and attitudes. For the practitioner, there is the benefit of being involved in something outside the daily routine of practice. ${ }^{2}$ Patients have also been found to approve of practitioner involvement in research, with the practice and practitioner's professional image being enhanced. ${ }^{2}$

As a result, a number of practice-based evaluation groups have become established, such as the Clinical Research Associates, mainly in the USA, and BRIDGE (Birmingham Research in Dental General practicE) and the PREP (Product Research and Evaluation by Practitioners) Panel in the UK, both being administered from the University of Birmingham's School of Dentistry. The latter group, co-ordinated by Burke and Crisp, is well established, has 27 members representing the wide diversity of general dental practitioners, and has completed over 40 evaluations of dental restorative materials in the UK, plus a number of clinical trials.

Worldwide, there appears to be an increasing demand for tooth-coloured restorations in posterior teeth. ${ }^{3}$ However, 


\begin{tabular}{|c|c|c|c|c|}
\hline & & Class I & Class II & Total \\
\hline \multirow{2}{*}{ MAXILLARY } & Premolar & 0 & 25 & 25 \\
\hline & Molar & 26 & 29 & 55 \\
\hline \multirow{2}{*}{ MANDIBULAR } & Premolar & 0 & 12 & 12 \\
\hline & Molar & 41 & 36 & 77 \\
\hline \multicolumn{2}{|l|}{ TOTAL } & 67 & 102 & 169 \\
\hline
\end{tabular}

\begin{tabular}{l|l|l|l|l|l|}
\multicolumn{2}{|l|}{ Table 2 Summary of data } & $\% 0$ & $\% 1$ & $\% 2$ & $\% 3$ \\
\hline Criteria & & 88 & 11 & $1^{*}$ & 0 \\
\hline \multirow{2}{*}{ Anatomical form } & Occlusal & 92 & 6 & $2^{*}$ & 0 \\
\cline { 2 - 7 } & Proximal & 95 & 1 & $4^{*}$ & 0 \\
\cline { 2 - 7 } Marginal adaptation & Gingival & 92 & 5 & $1^{*}$ & $2^{*}$ \\
\hline \multirow{2}{*}{$\begin{array}{l}\text { Enamel marginal } \\
\text { discolouration }\end{array}$} & Occlusal & 92 & 7 & 1 & 0 \\
\cline { 2 - 7 } & Proximal & 96 & 4 & 0 & 0 \\
\hline $\begin{array}{l}\text { Dentine margin } \\
\text { discolouration }\end{array}$ & Gingival & 95 & 5 & 0 & 0 \\
\hline \multirow{2}{*}{ Surface roughness } & Occlusal & 67 & 33 & 0 & 0 \\
\cline { 2 - 7 } & Proximal & 84 & 16 & 0 & 0 \\
\hline Colour match & & 17 & 82 & $1^{*}$ & 0 \\
\hline *Unacceptable scores & & & & & \\
\hline
\end{tabular}

although the clinical performance of resin composite restorations in posterior teeth has been shown to be similar to that of amalgam restorations, ${ }^{4}$ restorations in posterior composite may not be considered as cost-effective as amalgam because they have been considered to take 2.5 times longer to place than equivalent amalgam restorations. ${ }^{5}$ It would therefore be ideal if a tooth-coloured, easily-handled material were available as a replacement for amalgam. This has been considered to be the driver behind manufacturers' research into low-shrinkage composite materials and the introduction of fast setting glass ionomers with claimed improved physical properties. ${ }^{6}$

\section{Glass ionomer materials}

Glass ionomer cements were developed in the early 1970s. These materials comprised a fluoro-alumino-silicate (FAS) glass, mixed with a polyacrylic acid. ${ }^{7}$ Their popularity increased through the 1980s, and in 2000, these materials were used in the placement of circa 1.7 million restorations in the NHS in England and Wales, mainly in Class V non-load-bearing cavities. ${ }^{8}$ Principal advantages of glass ionomer materials include their good compressive strength, their reliable adhesion to tooth substance (which, in turn, reduces the need for the clinician to cut sound tooth substance to create retention for the restoration), and release of fluoride, which may inhibit the progress of caries around the restoration, although the literature on this is by no means unequivocal. ${ }^{10}$ Disadvantages of conventional materials included poor tensile and flexural strengths, which precluded the use of these materials in loadbearing cavities, moisture sensitivity, and poor aesthetics, because of their opacity. ${ }^{9}$

Resin-modified glass ionomer (RMGI) materials were developed, by the addition of circa five percent resin such as hydroxyethyl methacrylate (HEMA) within the structure, and these were introduced in the early 1980s. ${ }^{11}$ Since the resin was light activated in the majority of RMGI materials, these could be 'command set'. Nevertheless, RMGI materials may still be classified as glass ionomers by their ability to set without light curing. These materials addressed many of the deficiencies of the early glass ionomers. Their tensile and flexural strengths were much improved and their resistance to early aqueous attack was reduced. ${ }^{12}$ The aesthetics of restorations formed in these materials was also improved and the ability to finish and polish such restorations immediately following light curing has been considered to be a major advantage. ${ }^{12}$ However, the overall aesthetics, polishability and polish retention was not comparable to resin composite dental materials, and resistance to abrasive wear has been found to be less than for conventional materials. ${ }^{12,13}$

The most recently developed generation of glass ionomer materials have been termed fast-setting, high-strength, or reinforced glass ionomers. This group includes Chemflex (Dentsply, Weybridge, UK), Ketac-Molar Easymix (3M ESPE, Seefeld, Germany) and Fuji IX (GC, Tokyo, Japan). Manufacturers claim improved early physical properties and resistance to dissolution over conventional glass ionomers, ${ }^{14,15}$ this improvement being due to a reduction in the size of the glass particles in the matrix, allowing a faster speed of reaction between the glass and the polyacrylic acid. These materials are stiffer when mixed and have been termed 'packable' as a result. Manufacturers have considered that a reinforced glass ionomer material may be suitable for long-term temporary restoration of Class I and II cavities in permanent teeth (Chemflex), or permanent small Class I restorations (Ketac Molar Easy Mix), ${ }^{14,15}$ notwithstanding its suggested use in Class III and V cavities, Class I and II cavities in primary teeth, fissure fillings, core build-ups and atraumatic restorative treatment (ART) technique. ${ }^{14,15}$ However, the manufacturers of Fuji IX GP suggest that this material is suitable for Class I, II and $\mathrm{V}$ restorations in permanent and primary teeth. ${ }^{16} \mathrm{~A}$ faster setting version of this material is also available, with reported higher strength and higher wear resistance and a setting time which is half (at three minutes) that of the standard material. ${ }^{16}$

General dental practitioners are constantly faced with the requests of their patients, and these may include tooth coloured restorations in posterior teeth and low cost. It is therefore not surprising that anecdotal information became available that a number of UK general dental practitioners were using reinforced glass ionomers to restore cavities in loadbearing situations in posterior teeth. These may be placed in bulk, resulting in a saving in time when compared with the time-consuming incremental build-up required for posterior composite restorations. It is therefore the purpose of this clinical evaluation to retrospectively assess the performance of Fuji IX reinforced glass ionomer restorations placed in Class I and II cavities in three general dental practices in the UK. 


\section{MATERIALS AND METHODS}

The participating general dental practitioners were recruited as follows: one made contact with the Principal Investigator (FJTB) following comments made at a lecture, and the other two practitioners were recruited following correspondence sent to the members of the PREP Panel and the Masters in General Dental Practice students at the University of Birmingham. Inclusion criteria for the practitioners was that they placed Fuji IX restorations in load-bearing situations in posterior teeth, and/or that they would be able to find, in their regularly attending patients' mouths, a minimum of 30 such restorations. The three practitioners who agreed to participate in the study and abide by the study protocol were then requested to record data on the Fuji IX restorations which were found to be present in the mouths of patients attending for routine dental examination. They were given training in the methods of assessment, which were based on the USPHS criteria ${ }^{17}$ for restoration assessment, and a proforma was designed for this purpose in order to record presence/absence of the restoration, presence of secondary caries, anatomic form, margin adaptation, margin discolouration, surface roughness and colour match. Ethical approval was not considered necessary since restorations were assessed when patients attended for their routine dental examination, the work being classified as a clinical audit.

\section{RESULTS}

The three practitioners who responded to the invitation to participate in the study were males aged 60 years, 37 years and 36 years.

The distribution of restorations which were examined in the study is presented in Table 1, indicating that over three quarters (78\%) of restorations were placed in molar teeth. Overall, 116 patients were included in the assessment, of whom 43 were male (average age 46 years [range 13-72 years]) and 73 were female (average age 44 years [range 18-76 years]). A total of 169 restorations were examined, of which 67 were Class I and 102 were Class II. The mean age of restorations at examination was 25 months, ranging from five months to 56 months. Of the restorations examined, $98 \%(n=166)$ were found to be present and intact. No secondary caries was detected clinically. Three restorations were found to have fractured - all were replaced by another Fuji IX restoration. The overall performance of the restorations is presented in Table 2.

The participating practitioners were found to have placed broadly similar numbers of restorations, namely, 45 (SC), 56 (CS) and 68 (JB). Two practitioners diagnosed no failures, with the three failures (vide supra) occurring in the practice in which the greatest number of restorations was assessed. The mean age of the restorations included in the study was 34 months (SC), 26 months (JB) and 17 months (CS).

\section{DISCUSSION}

The present study presents 'real world' data from general dental practice and the restorations assessed in the study were therefore placed within the time pressures pertaining to busy UK dental practices. The participating practitioners were given training in the use of USPHS criteria. In an ideal world, an independent observer would have attended the participating practices at pre-arranged appointment times. However, this would necessarily have caused disruption to the practice schedule, notwithstanding the cost of sending the observer to the practices. Given these logistical and budgetary constraints, it was nevertheless decided to carry out the study and it was decided to use the present work as a preliminary study which could be repeated under more rigorous and controlled conditions should the results be of sufficient interest. Again, to avoid disruption and the use of patient time, it was decided to examine the restorations only when the patients attended for routine examination.

Two of the participating practitioners placed the Fuji IX restorations themselves, while the third (CS) took over a practice in which his predecessor had placed the restorations. It could be argued that this practitioner would make a more objective assessment of the restorations than the two dentists who had placed the restorations themselves, but examination of the data from the practitioners does not reveal any difference between the one practitioner who did not place the restorations and the other two who assessed the restorations which they, themselves, had placed. The restorations were all placed under private contract between practitioner and patient, as NHS regulations in force at the time of the study precluded the placement of tooth-coloured restorations in load-bearing situations in posterior teeth.

Disadvantages of conventional glass ionomer materials included poor tensile and flexural strengths, ${ }^{9}$ which, in effect, precluded the use of these materials in load-bearing cavities, with a failure rate two times that of amalgam being noted even in the less demanding conditions of restorations in primary teeth. ${ }^{18,19}$ Qvist and colleagues, reporting the eight-year results of RMGI restorations in primary teeth, considered that these materials should be preferred to conventional glass ionomer materials. ${ }^{20}$ However, there is a paucity of data on the performance of any type of glass ionomer in load-bearing situations in posterior teeth in adult patients. The present study, while lacking the scientific rigour of controlled evaluations, does appear to suggest that a reinforced glass ionomer, Fuji IX, may perform satisfactorily in the short term in Class I and II cavities. It could be considered that these results suggest a need for the extension of the present work to a longer period of time and/or a more controlled investigation involving an independent examiner.

Results of one study have suggested that Fuji IX has a wear resistance not dissimilar to a resin composite. ${ }^{21}$ Another ${ }^{22}$ has suggested that the early wear resistance of highly-viscous glass ionomers should be improved, but also considered that these materials may compete with composites as far as long-term wear is concerned. The results of the present study suggest that wear of the occlusal surfaces of the restorations assessed is not a problem during the period of this assessment, ie in the short term.

Results from an overview of ten cross-sectional studies, which included 2,137 glass ionomer restorations, have indicated that secondary caries is the reason for failure of between $17 \%$ and $40 \%$ of glass ionomer restorations..$^{23}$ Additionally, the benefit of fluoride release from glass ionomer restorations in respect of cariostasis is not clear cut. ${ }^{10}$ However, the results of the present study suggest that secondary caries may not be problem associated with reinforced glass ionomer restorations at two years. Again, further long-term studies are indicated to more fully quantify the cariostatic effect of glass ionomer restorations placed in load-bearing cavities. 


\section{CONCLUSION}

Within the limitations of the study, reinforced glass ionomer restorations placed in load-bearing situations, in patients attending three dental practices in the UK, were found to be performing satisfactorily at two years. Further investigations, of improved rigour, may now be indicated to more fully assess the performance of such restorations in the long term.

The financial support of GC Europe is acknowledged.

1. Burke F J T, McCord J F. Research in general dental practice - problems and solutions. Br Dent J 1993; 175: 396-398.

2. Burke F J T, Crisp R J, McCord J F. Research in dental practice: a SWOT analysis. Dent Update 2002; 29: 80-87.

3. Burke F J T. Amalgam to tooth-coloured materials - implications for clinical practice and dental education: governmental restrictions and amalgam-usage survey results. J Dent 2004; 32: 343-350.

4. Manhart J, Chen H Y, Hamm G, Hickel R. Review of the clinical survival of direct and indirect restorations in posterior teeth of the permanent dentition. Oper Dent 2004; 29: 481-508.

5. Burke F J T. Attitudes to posterior composite filling materials: a survey of 80 patients. Dent Update 1989; 16: 114-120.

6. Hassan M A, Watson T F. Conventional glass ionomers as posterior restorations. A status report for the American Journal of Dentistry. Am J Dent 1998; 11: 36-45.

7. Wilson $A D$, Kent $B$ E. A new translucent cement for dentistry. The glass ionomer cement. Br Dent J 1972; 132: 133-135.

8. Dental Practice Board. Digest of statistics, April 2002 - March 2003. Eastbourne: Dental Practice Board, 2003.
9. Combe E C, Burke F J T, Douglas W H. Clinical dental materials. Kluwer Academic Publishers, 1999.

10. Randall R C, Wilson N H F. Glass ionomer restoratives: a systematic review of a secondary caries treatment effect. J Dent Res 1999; 78: 628-637.

11. Sidhu S K, Watson T F. Resin modified glass ionomer materials. A status report for the American Journal of Dentistry. Am J Dent 1995; 8: 59-67.

12. Kao E C, Rezvan E, Johnson W M. Microhardness as an indicator for finishing time in ionomer restorations. J Dent Res 1994; 73: 220 [abstract no. 945].

13. Momoi Y, Hirosaki K, Kohno A, McCabe J F. In vitro toothbrush-dentifrice abrasion of resin-modified glass ionomers. Dent Mater 1997; 13: 82-88.

14. Dentsply De Trey GmbH Professional Research. Chemflex technical manual. pp 25. Germany: Dentsply De Trey, 1998.

15. Ketac Molar quick product brochure. www 3mespe.com.

16. GC Fuji IX and Fuji IX GP fast manual. www.gceurope.com.

17. Ryge G. Clinical criteria. Int Dent J 1980; 30: 347-357.

18. Welbury R R, Walls A W G, Murray J J, McCabe J F. The 5-year results of a clinical trial comparing a glass polyalkenoate (ionomer) cement restoration with an amalgam restoration. Br Dent J 1991; 170: 177-181.

19. Ostlund J, Moller K, Koch G. Amalgam, composite resin and glass ionomer cement in class II restorations in primary molars - a three year clinical evaluation. Swed Dent J 1992: 16: 81-86.

20. Qvist V, Manscher E, Teglers P T. Resin-modified and conventional glass ionomer restorations in primary teeth: 8-year results. J Dent 2004; 32: 285-294.

21. Yap A U J, Teo J C M, Teoh S H. Comparative wear resistance of reinforced glass ionomer restorative materials. Oper Dent 2001; 26: 343-348.

22. Van Duinen R N B, Kleverlaan C J, de Gee A J, Werner A, Felizer A J. Early and long-term wear of "Fast-set" conventional glass ionomer cements. Dent Mater 2005; $21: 716-720$

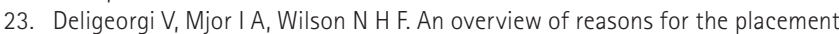
and replacement of restorations. Primary Dent Care 2001; 8: 5-11. 